\title{
A surface reflectance scheme for retrieving aerosol optical depth over urban surfaces in MODIS Dark Target retrieval algorithm
}

\author{
Pawan Gupta ${ }^{1,2}$, Robert C. Levy ${ }^{2}$, Shana Mattoo ${ }^{2,3}$, Lorraine A. Remer ${ }^{4}$, and Leigh A. Munchak ${ }^{2,3}$ \\ ${ }^{1}$ Goddard Earth Sciences Technology And Research (GESTAR), Universities Space Research Association (USRA), \\ Columbia, MD, USA \\ ${ }^{2}$ NASA Goddard Space Flight Center, Greenbelt, MD 20771, USA \\ ${ }^{3}$ Science Systems and Applications, Inc, Lanham, MD 20709, USA \\ ${ }^{4}$ JCET, University of Maryland - Baltimore County, Baltimore, MD 21228, USA \\ Correspondence to: Pawan Gupta (pawan.gupta@nasa.gov)
}

Received: 25 December 2015 - Published in Atmos. Meas. Tech. Discuss.: 18 January 2016

Revised: 28 June 2016 - Accepted: 29 June 2016 - Published: 26 July 2016

\begin{abstract}
The MODerate resolution Imaging Spectroradiometer (MODIS) instruments, aboard the two Earth Observing System (EOS) satellites Terra and Aqua, provide aerosol information with nearly daily global coverage at moderate spatial resolution (10 and $3 \mathrm{~km})$. Almost 15 years of aerosol data records are now available from MODIS that can be used for various climate and air-quality applications. However, the application of MODIS aerosol products for airquality concerns is limited by a reduction in retrieval accuracy over urban surfaces. This is largely because the urban surface reflectance behaves differently than that assumed for natural surfaces. In this study, we address the inaccuracies produced by the MODIS Dark Target (MDT) algorithm aerosol optical depth (AOD) retrievals over urban areas and suggest improvements by modifying the surface reflectance scheme in the algorithm. By integrating MODIS Land Surface Reflectance and Land Cover Type information into the aerosol surface parameterization scheme for urban areas, much of the issues associated with the standard algorithm have been mitigated for our test region, the continental United States (CONUS). The new surface scheme takes into account the change in underlying surface type and is only applied for MODIS pixels with urban percentage (UP) larger than $20 \%$. Over the urban areas where the new scheme has been applied (UP> 20\%), the number of AOD retrievals falling within expected error (EE \%) has increased by $20 \%$, and the strong positive bias against ground-based sun photometry has been eliminated. However, we note that the new retrieval introduces a small negative bias for AOD values less
\end{abstract}

than 0.1 due to the ultra-sensitivity of the AOD retrieval to the surface parameterization under low atmospheric aerosol loadings. Global application of the new urban surface parameterization appears promising, but further research and analysis are required before global implementation.

\section{Introduction}

In large concentrations, aerosols near the surface (also called particulate matter or PM) are air pollutants. As urbanization and industrialization have amplified many folds during the last few decades (United Nations, 2014), air quality has become a global public health concern, especially in densely populated urban areas. In some cities, urban PM concentrations are at dangerous levels, 5 to 10 times higher than World Health Organization (WHO) guidelines. Although urban areas only represent about half a percentage of the total Earth's surface and about $3 \%$ of Earth's land surface, half of the human population lives in these areas. According to the new projections, two-thirds of the human population will live in urban areas by 2025 ; therefore, it is critical to monitor air quality (aerosol or PM), especially as relating to human exposure in populated regions around the world.

In economically developed countries such as the United States, and some European nations, surface PM concentrations and air quality are monitored by thousands of groundbased monitoring stations (Cooper et al., 2012). While the density of measurements in the USA may be sufficient for 
metropolitan-scale mapping, they are not dense enough for local or neighborhood scales. Also, about $30 \%$ of counties in the USA are without any PM monitoring. In contrast, most other countries, especially in developing nations, have few or no surface PM monitors and cannot measure the urban population's exposure to PM.

In the last few decades, satellites are increasingly being used to offer a global perspective on many atmospheric variables. One of these is aerosol optical depth (AOD), which is a measure of aerosol loading, integrated through the atmospheric column. As retrievals of AOD are increasing in their spatial resolution, coverage and accuracy, environmental monitoring agencies are increasingly looking to satellites to cover the gaps in aerosol monitoring. Although it is not straightforward, many studies (Wang and Christopher 2003; Gupta et al., 2006; Gupta and Christopher, 2009; Hoff and Christopher, 2009; van Donkelaar et al., 2010, 2015; Liu et al., 2010) are trying to link satellites retrievals of AOD to surface concentrations of $\mathrm{PM}_{2.5}$ or $\mathrm{PM}_{10}$ (PM having aerodynamic diameters of 2.5 or 10 micrometers, respectively).

In addition to its role in air quality and public health, aerosols are considered an essential climate variable (e.g., IPCC, 2007), and remote sensing of AOD has evolved, primarily, to address climate-related questions. Decisions about aerosol products, product resolution and tolerance of poorer quality retrievals have been made to maximize the effectiveness of these products for climate, not air-quality, applications. For example, poor quality retrievals over urban surfaces that represent so little of the Earth's surface have a negligible effect on the climate question, and so retrieval algorithms originally were tuned to ignore the special nature of the urban environment. There are several satellite-based AOD products and each combination of satellite/retrieval algorithm has its own advantages and limitations. One satellite/algorithm pair with a climate-oriented aerosol product is the MODerate resolution Imaging Spectroradiometer (MODIS) Dark Target (MDT) algorithm. The MDT algorithm is mature, having been developed 20 years ago (Kaufman et al., 1997b; Tanré et al., 1997) for retrieval of AOD over primarily vegetated (e.g., dark) land surfaces and remote oceans. It is now running as Collection 6 (Levy et al., 2007a, b, 2013), and the standard AOD product (nominal $10 \mathrm{~km}$ spatial resolution) is generally unbiased over global land regions, a requirement for climate applications.

The standard MDT product, while well suited to answer climate questions, has many shortcomings when used for airquality monitoring. The first, and most important, is that PM is defined as the concentration of particles in the surface layer of the atmosphere where people can be affected by the pollution, while the MDT product measures the aerosol loading (AOD), integrated from this surface layer all the way to the top of the atmosphere. Correlation between column AOD and surface PM depends on the vertical profile of aerosol concentration, which is not measured by MODIS. However, the other problem is that the MDT retrieval, while nearly un- biased compared with the full set of sun photometer (SP) measurements in the Aerosol Robotic Network (AERONET) database, has strong biases for particular surface types.

MDT over land was designed for retrieval over vegetated and other "dark" surface regions. MDT does not provide aerosol retrieval over very bright surface (i.e., desert) and over snow and ice regions. In addition, several validation studies have shown that MDT AOD retrievals over urban area are positively biased with respect to AERONET AODs (Levy et al., 2010; Jethva et al., 2007; Hyer et al., 2011; Gupta et al., 2013; Munchak et al., 2013). These studies have shown that the major source of bias in the MDT over cities is that the city surface does not behave as a vegetated "dark" target.

Several other research attempts have been made to change the surface scheme in the MDT for particular urban regions and produce better AOD retrievals for those specific cities (de Almeida Castanho et al.,2007, 2008; Li et al., 2005; Wong et al., 2011; Zha et al., 2011; Li et al., 2012; Escribano et al., 2014; Jäkel et al., 2015). Instead of a retrieval focused on only one city, we seek a surface parameterization that is valid for cities across the globe. This will lead to more accurate AOD retrievals, which can be utilized for air-quality applications and research, including estimating urban population exposure to aerosols. In this paper, we have developed a surface characterization for cities in the continental US (CONUS) region, applied it to the MDT algorithm and evaluated the results. In Sect. 2 we introduce MODIS, the MDT algorithm and its current limitations over cities. Section 3 discusses study region and various data sets utilized in this study. Section 4 describes the new surface parameterization, whereas results and impact of new surface scheme on MDT AOD retrievals over CONUS regions are discussed in Sect. 5. Section 6 covers implications of the new surface scheme over global regions and its limitations and challenges. We summarize the results and future directions in Sect. 7.

\section{MODIS and the Dark Target algorithm}

MODIS sensors have been observing the Earth system (atmosphere, land and ocean) on board two satellites, since 1999 on Terra and since 2002 on Aqua. MODIS observes top-of-the-atmosphere (TOA) radiance in 36 spectral bands, which are used to derive geophysical information about atmosphere, land and ocean. The spatial resolution varies from $250 \mathrm{~m}$ to $1 \mathrm{~km}$ depending on spectral band. The large swath width of MODIS ( $2300 \mathrm{~km})$ enables global coverage in 12 days. Data are separated into 5 min segments known as granules.

Since MODIS measures the reflectance of the Earth's system, the measured radiation contains information about atmospheric properties as well as Earth's surface. In some spectral bands, the surface dominates the signal, whereas the atmosphere dominates in other bands. The strategy then is to use the right combinations of spectral bands to retrieve a par- 
ticular aspect of the combined Earth's system. Specifically, the MDT is used to derive global aerosol properties under cloud/snow/ice-free conditions.

The theoretical basis of the MDT algorithm has remained constant from its original at-launch version, although individual sub-modules have been continuously evolving. While a summary of the algorithm is provided here, the reader is encouraged to read the references for details of the algorithm assumptions and structure and its evolution through different versions over time (Remer et al., 2005; Levy et al., 2007a, b, 2013).

The five main components of the MDT aerosol retrieval algorithm are (1) pixel selection and aggregation, including cloud masking and other filtering; (2) separating the surface from the atmosphere; (3) assumptions about the aerosol (e.g., aerosol models); (4) matching observed TOA spectral reflectance to lookup tables; and (5) inferring the ambient aerosol conditions (model weightings and total AOD). There are two separate retrievals, one over ocean and one over land, and the results of these retrievals and associated diagnostics are available in a single data file. Each retrieval result and each diagnostic are independent science data sets (SDSs) within the produced file. In production, collectively these SDSs within the single file are known as the MxD04 product, where $\mathrm{x}$ is "O" for Terra and "Y" for Aqua, and the "04" denotes the level 2 aerosol products. Products (SDSs) include the total AOD (at $0.55 \mu \mathrm{m}$ ), spectral AOD and diagnostics describing the choice of retrieval solutions, plus quality assurance criteria and expected confidence in the retrieved AOD. The standard MxD04 product, known as MxD04_L2, is provided at a nominal (nadir) spatial resolution of $10 \mathrm{~km}$. In the recent release of MODIS Collection 6 (C6) data version, there is also a MxD04_3K product, which is at $3 \mathrm{~km}$ spatial resolution (nadir) and available globally. The standard C6 products have gone through initial validation (e.g., Levy et al., 2013; Munchak et al., 2013; Remer et al., 2013).

The MODIS retrieval codes are run in an operational environment to create C6 products. This includes infrastructure for managing file formats and also for processing entire granules of MODIS data. In this work, we also make use of the so-called "stand-alone" version of the MODIS Dark Target (S-MDT) retrieval code (e.g., Levy and Pinker, 2007). The S-MDT is stripped of all routines for cloud masking, pixel selection and pixel aggregation, instead operating on a pixel-by-pixel basis. Inputs are a single set of TOA spectral reflectance values, plus sun-satellite geometry and geolocation. Outputs are the retrieved AOD and most of the diagnostics contained in the standard output. Since the standard C6 data (e.g., the $10 \mathrm{~km}$ retrievals) include the TOA spectral reflectance used for each retrieved AOD value, the data provided in the C6 output file (e.g., MxD04_L2) can be recycled through the S-MDT algorithm to retrieve the same AOD value as provided within the C6 product. Thus, the S-MDT can be easily modified to test different assumptions within the retrieval, including surface reflectance assumptions. The insights gleaned from the S-MDT exercises can then be transferred back to modify the full (operational) retrieval code, and tests (and statistics) can be performed for global data.

\subsection{MDT surface characterization and urban aerosol retrievals}

The land surface is too variable to apply an explicit model to describe its spectral optical properties. Thus MDT uses an empirical parameterization based on only three MODIS bands. Kaufman et al. (1997a, 2002) noted that for most vegetated and dark-soiled land surfaces, observations showed that surface reflectance in a blue wavelength $(0.47 \mu \mathrm{m})$ and red wavelength $(0.65 \mu \mathrm{m})$ were about one-quarter and onehalf of the surface reflectance in a shortwave infrared (SWIR, $2.1 \mu \mathrm{m}$ ) wavelength band, respectively. With such a SWIRto-visible (SWIR-VIS) surface relationship theoretically existing on a global scale (e.g., Kaufman et al., 2002), one can construct three equations and three unknowns using the satellite-measured reflectance at the three wavelengths to separate the surface and aerosol contributions (Levy et al., 2007b).

The current operational version (C6) of the MDT algorithm is still based on the SWIR-VIS surface relationships, but it also adjusts the relationship for vegetation amount and geometry as determined by a variant of the normalized difference vegetation index based on SWIR bands (NDVISWIR) and the scattering angle of the solar/surface/satellite observing geometry. The NDVI SWIR $_{\text {is defined as }}$

NDVI $_{\text {SWIR }}=\frac{\left(\rho_{1.24}^{m}-\rho_{2.12}^{m}\right)}{\left(\rho_{1.24}^{m}+\rho_{2.12}^{m}\right)}$

where $\rho_{1.24}^{m}$ and $\rho_{2.12}^{m}$ are the measured reflectances by MODIS at wavelengths 1.24 and $2.12 \mu \mathrm{m}$, respectively. NDVI $_{S W I R}$ is less affected by aerosols in the atmosphere than the traditional NDVI based on red and near-infrared channels (Levy et al., 2007b).

Although the SWIR-VIS assumption characterizes "dark" surfaces on a global scale, it fails to account for all surface types, especially for anthropogenic modifications to natural land surfaces. As a land surface transitions from natural vegetation to manmade structures such as buildings and roads, the global SWIR-VIS relationship is violated. This was noted in Levy et al. (2007b, 2009). In addition, de Almeida Castanho et al. (2007) analyzed the SWIR-VIS relationship over Mexico City and found that the ratios of SWIR-red are much higher (0.73-0.76) than what is assumed in the MDT global algorithm (0.50-0.55). They also found that the SWIR-VIS relationship strongly depends on differences in urbanization fraction. Using the global values for surface ratio when the actual ratio is much higher will underestimate the visible surface reflectance and the resulting aerosol contribution will be overestimated. Munchak et al. (2013) used the dense AERONET Distributed Regional Aerosol Gridded Observation Networks (DRAGONs) (Holben et al., 2011) that op- 
erated in Washington DC-Maryland during 2011 to identify the urban high bias and link that bias to the urban percentage (UP) around each AERONET site. While there have been attempts to improve the MDT aerosol retrieval on the local or even regional scale, no attempt has been made to date to develop a general improved surface reflectance parameterization that can be applied to the global retrieval. In this study, we develop a new SWIR-VIS scheme that accounts for NDVI $I_{S W I R}$ and scattering angle but also accounts for the UP.

\section{Data and study region}

We explore whether MDT surface parameterization can be modified to account for urban surface properties. We start with the research S-MDT version (Levy and Pinker, 2007; and http://darktarget.gsfc.nasa.gov) and develop a replacement SWIR-VIS parameterization that includes dependence on UP. To develop the replacement SWIR-VIS parameterization, we rely on two data sets. These are the MODIS Land Cover Type and the MODIS Land Surface Reflectance products. The MDT algorithm with the replacement SWIR-VIS parameterization, we denote as the C6-Urban (C6U) version.

To test the C6U retrieval, we compare the retrieved AOD with the SP measurements taken at standard AERONET sites, as well as AERONET's DRAGONs during the Maryland deployment of the "Deriving Information on Surface conditions from Column and Vertically Resolved Observations Relevant to Air Quality" (i.e., DISCOVER-AQ) (Holben et al., 2010) experiment.

\subsection{AERONET}

AERONET is NASA's global ground network of SPs that make measurement of direct transmitted solar light during daylight hours (Holben et al., 1998), and from that measurement we derive spectral AOD. There are currently about 300 sites around the globe with more than 1 year of regular observations; in addition, dense DRAGONs, while more limited in time, make dense measurements over urban/suburban areas. DRAGONs have tended to be deployed in support of large field experiments, including DISCOVER-AQ.

The spectral measurements from the SPs are used to derive AODs in respective spectral bands. The typical frequency of measurements is every $15 \mathrm{~min}$ and the spectral bands are generally centered at 340, 380, 440, 500, 675, 870 and $1020 \mathrm{~nm}$. Here we use the Ångström coefficient to interpolate AERONET AOD to $550 \mathrm{~nm}$. AERONET data products are available as unscreened (level 1.0), cloud screened (level 1.5) and cloud screened and quality assured (level 2.0). In this study, level 2.0 AERONET AOD data are considered as ground truth to validate the satellite-retrieved AOD data. The reported uncertainty in AERONET AOD is of the order of 0.01-0.02 (Eck et al., 1999). There are about 135 CONUS
AERONET stations collocated with MODIS Aqua for the 2003 to 2012 time period. This includes 39 DRAGON sites, permanent AERONET sites and temporary AERONET sites operated for different periods between 2003 and 2012. Only the sites located over land are considered in this study.

The DRAGON sites in Maryland DISCOVER-AQ deployment were operated for about 6 weeks from 1 July to 15 August 2011. The sites were located in the Washington DC-Baltimore metropolitan area. The network provided useful AOD measurements over urban, agricultural, coastal and mountain landscapes over the Washington DC metropolitan area.

\subsection{MODIS Land Cover Type}

The MODIS Land Cover Type product (MCD12Q1) for the year 2011, at $500 \mathrm{~m}$ resolution, has been used to identify urban surfaces in the new surface scheme. This is a yearly product, based on a trained classification algorithm that uses five different classification schemes (Friedl et al., 2010), and is derived using observations from both MODIS sensors. There are 17 land cover classes as defined by the International Geosphere-Biosphere Program (IGBP). The land cover class defined as "urban and built-up area" has been extracted and UP at $0.1 \times 0.1^{\circ}$ resolution (approximately equivalent to the $10 \mathrm{~km}$ MODIS AOD product resolution) is calculated. Figure 1 shows the map of UP for the CONUS region. This map of UP has been used in the C6U algorithm to define and apply the new surface scheme for each MODIS $10 \mathrm{~km}$ AOD retrieval. We have done a separate analysis (not shown in the paper) which demonstrates that urban land use at $10 \mathrm{~km}^{2}$ spatial resolution only changes by $1-3 \%$ over a period of 10 years. Because we are working with range of urban percent, as opposed to a sharp threshold, this should not impact our surface characterization from year to year. Therefore, we decided to use UP from the year 2011 to apply on MODIS records from 2003 to present.

\subsection{MODIS Land Surface Reflectance}

The surface parameterization in the MDT algorithm was based on performing atmospheric correction of MODISmeasured reflectance near AERONET sites, which led to formulation of the empirical SWIR-VIS relationships (e.g., Levy et al., 2007b, 2013). Rather than repeating this exercise, we rely on the MODIS-derived land spectral surface reflectance product because it is available and has been validated with similar atmospheric correction exercises. Specifically, we use the MODIS 8-day, clear-sky surface reflectance product (MOD09A1/MYD09A1; Vermote and Kotchenova, 2008) for the first seven bands of MODIS, which are gridded at $500 \mathrm{~m}$ resolution. These are same bands used for the MDT aerosol retrieval.

The MxD09A1 product is created by identifying the "clearest" observations of a scene during an 8-day period 


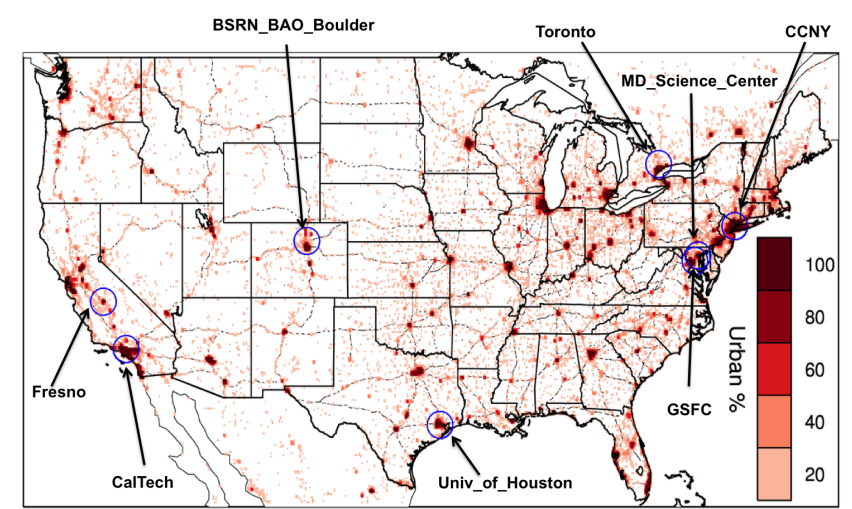

Figure 1. The urban percentage map for the continental United States derived from MODIS Land Cover Type product (MCD12Q1) at $0.1 \times 0.1^{\circ}$ resolution to be used in the new surface characterization scheme inside the MODIS DT AOD retrieval algorithm. The circles show individual AERONET stations for which results are presented in Fig. 5 and Table 4. Dotted lines on the map show major highways.

Table 1. Uncertainty in surface reflectance product (MYD09) as obtained by validation exercise and reported at http://landval.gsfc. nasa.gov/ (accessed on 14 May 2016).

\begin{tabular}{lccr}
\hline & \multicolumn{3}{c}{ Uncertainty in surface reflectance } \\
\hline AERONET Site & $\begin{array}{r}\text { Band 1 } \\
\text { (red) }\end{array}$ & $\begin{array}{c}\text { Band 3 } \\
\text { (blue) }\end{array}$ & $\begin{array}{r}\text { Band 7 } \\
\text { (NIR) }\end{array}$ \\
\hline GSFC & 0.0055 & 0.0118 & 0.0009 \\
MD_Science_Center & 0.0094 & 0.0214 & 0.0009 \\
BSRN_BAO_Boulder & 0.0025 & 0.0068 & 0.0042 \\
Bondville & 0.0036 & 0.0096 & 0.0035 \\
\hline
\end{tabular}

and performing generic atmospheric corrections (estimating aerosol type and AOD) to obtain surface reflectance values. These pixels are selected for low view angle, the absence of clouds or cloud shadow, and low aerosol loading. Pixels identified as snow/ice, adjacent to cloud, fire, cirrus, inland water or high aerosols loading are excluded. This surface reflectance product is officially validated as a stage 3 product. Validation of the MxD09A1 product has been performed over 150 AERONET sites (http://modis-sr.ltdri.org) by using AERONET measurements (spectral AOD, water vapor) to perform a detailed atmospheric correction. Overall, $87 \%$ of "good" pixels of red band reflectance are within the error bars defined as $\pm(0.005+5 \%)$ (http://modis-sr.ltdri.org/ pages/validation.html). A "good" quality surface reflectance retrieval is determined when the atmosphere has no cloud, cloud shadow or high aerosol loading.

Validation results show that the red and SWIR bands are more accurate than the blue band, and uncertainty increases over urban areas in all bands, but especially in the blue. Early validation results suggested that for urban surfaces, typified by Hamburg, Germany, the percentage of surface reflectance retrievals falling within the above stated error bars were $70 \%$ and $100 \%$ for the red and SWIR channels, respectively, but less than $10 \%$ for the blue channel (Vermote and Kotchenova, 2008). Also, this site exhibited a consistent high bias of 0.01 reflectance in band $4(0.54 \mu \mathrm{m})$. However, Vermote and Kotchenova (2008) explain that the Hamburg site suffered from a very small sample size (only 2 clear days during the month of study). Non-urban sites had much greater sample sizes and much better validation statistics, although overall the blue channel still lagged behind the other channels with only $50 \%$ of retrievals falling within the error bars (Vermote and Kotchenova, 2008). More recent validation provided from the web site (http://landval.gsfc.nasa.gov/) continues to show the blue channel reflectance having greater uncertainty than either red or SWIR, especially for urban sites. Table 1 lists the validation results and uncertainty in surface reflectance for three bands at four sites. Bondville is the most rural of the sites. MD_Science_Center in downtown Baltimore is the most urban. The blue band always has the highest uncertainty, which increases as the surface transitions from rural to urban.

Despite these uncertainties, we will make use of all three wavelengths bands, because the MxD09A1 provides the most complete characterization of surface reflectance at the spatial scales necessary for our study. We are fully aware that the high uncertainty in the blue band can lead to errors in surface reflectance ratios and thus to errors in retrieved AODs, specifically under low aerosol conditions when the algorithm is most sensitive to accurate surface reflectance values. Further discussion of the MxD09A1 product from the perspective of this study is provided in Sect. 7.

\section{Developing the new surface reflectance scheme}

For the MDT algorithm to include an urban surface reflectance scheme, it must

1. reduce the bias between MDT retrievals and SP measurements in urban areas;

2. improve the retrievals in urban areas without degrading retrieval quality in non-urban areas;

3. have an operational path that identifies whether or not to apply the new scheme;

4. slip into the structure of the existing operational algorithm without requiring extensive additional modifications.

The first step to meeting these requirements is to characterize the unique surface reflectance behavior of urban surfaces. Although there have been previous studies which have characterized surface reflectance over urban areas, they are limited to being near AERONET sites, where atmospheric 
correction could be applied. These local relationships have not been shown to represent the SWIR-VIS relationship over larger areas. Relationships derived in this limited database are skewed towards surface characteristics of AERONET locations.

By using the MODIS Land Surface Reflectance product (MOD09) as described in Sect. 3, we have a data set with global coverage, as opposed to atmospheric correction exercises for individual sites (which use observed ground-based aerosol properties to derive surface reflectance).

To create our urban surface parameterization, we start with the MOD09 product in its native resolution (e.g., $500 \mathrm{~m}$ pixels). The MODIS $500 \mathrm{~m}$ resolution surface reflectance values are quality controlled and averaged into a $0.1 \times 0.1^{\circ}$ grid, roughly equivalent to the MDT $10 \mathrm{~km}$ AOD retrieval. Thus instead of point measurements of surface reflectance, we now have spatial maps of surface reflectance covering the entire study region. At the same time, we used the offline land cover database (MCD12Q1) to identify which pixels were urban. The UP is defined as the percentage of pixels $(500 \mathrm{~m})$ identified as urban land cover type within each $0.1 \times 0.1^{\circ}$ degree grid.

We expect that different cities will exhibit different surface reflectance relationships for the same UP, because the natural vegetation background is different. Therefore, we

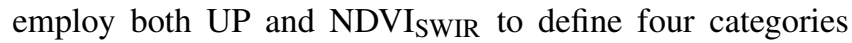
of surface type. For example, Brooklyn (New York), with its sidewalk plantings of deciduous trees, may look different than Los Angeles (California), which uses palm tree plantings for its sidewalks. These four categories are separated into low vegetation and high UP $\left(\mathrm{NDVI}_{\mathrm{SWIR}}<0.20\right.$ and $\mathrm{UP}>50 \%)$, low vegetation and low UP $\left(\mathrm{NDVI}_{\mathrm{SWIR}}<0.20\right.$ and $20 \%<\mathrm{UP}<50 \%$ ), high vegetation and relatively low UP (NDVI SWIR $>0.20$ and $20 \%<\mathrm{UP}<70 \%)$ and high vegetation and high UP (NDVI SWIR $>0.20$ and UP $>70 \%)$. These bin thresholds were chosen to optimize the correlation coefficient between wavelengths in each bin. We have also restricted this analysis to only over the urban areas by selecting pixels with UP larger than $20 \%$ so that the retrieval over natural surfaces does not contribute to the formulation of the parameterization. For UP $<20 \%$, we use the $\mathrm{C} 6$ assumptions for surface reflectance (using NDVI SWIR $_{\text {only). }}$

Figure 2 provides the surface reflectance spectral relationships between SWIR and VIS, defined for the four different categories based on the combinations of NDVI SWIR $_{\text {and }}$ UP. The four regression lines in the figures are calculated for each of the four categories using bins of equal number of points. We still derive the regression coefficients from the cloud of points (shown as gray color) but bin the data to help visualize the differences from regime to regime. We note that the slopes of the regression between the blue and red wavelengths are not strongly dependent on differences in the UP

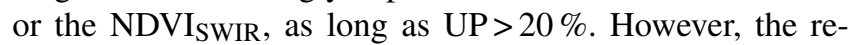
gressions between the red and SWIR wavelengths are indeed dependent on the nuances of the urban surface. The values
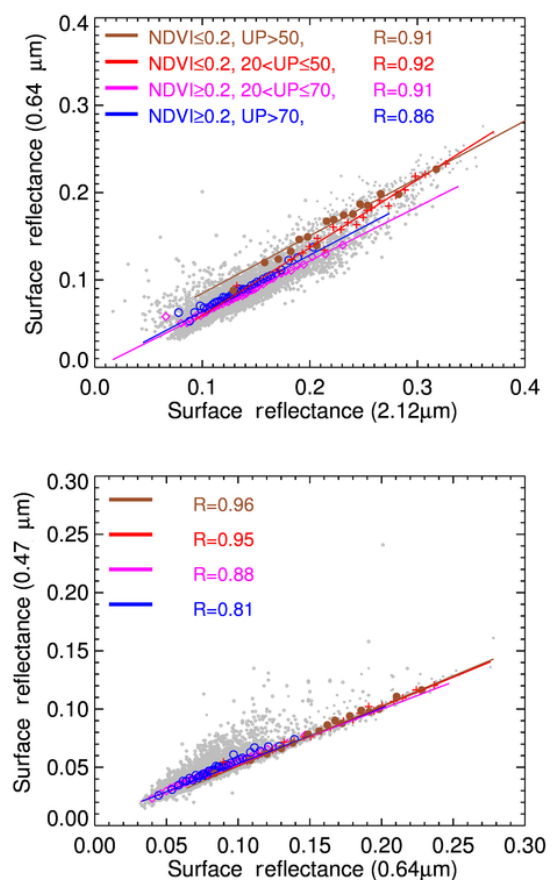

Figure 2. The $0.65 \mu \mathrm{m}$ vs. $2.12 \mu \mathrm{m}$ surface reflectance (top panel) and the $0.47 \mu \mathrm{m}$ vs. $0.65 \mu \mathrm{m}$ surface reflectance (bottom) for four

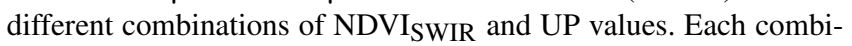

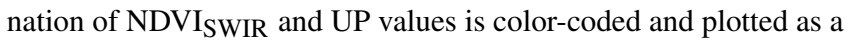
different symbol. The standard regression using least absolute deviation method applied and the resulting regression lines are plotted. The regression parameters corresponding to each bin of NDVI SWIR and UP are presented in Table 2 and the linear correlation coefficient $(R)$ is presented in the figure. These four regression lines represent the new surface scheme for revised urban aerosol retrieval in the MDT.

of the regression statistics ("slope" and "yint") for each of the four categories are given in the Table 2. Here slope and intercept are calculated based on the least absolute deviation method to avoid the extreme outliers. Mean of the absolute deviation (AbsStd) of the results and $Y$ (result is calculated VIS reflectance and $Y$ is original VIS reflectance) is also provided in Table 2. This provides a quantitative indicator of uncertainties in surface reflectance of visible bands in the new surface scheme.

The regression statistics provide the information needed to relate the surface reflectance $\left(\rho^{s}\right)$ at 0.65 and $0.47 \mu \mathrm{m}$ to that at $2.12 \mu \mathrm{m}$. We take into account the effects of geometry by relying on the Levy et al. (2007b) parameterization for scattering angle, $\theta$.

$$
\begin{aligned}
& \rho_{0.65}^{s}=\rho_{2.12}^{s} \cdot M_{\frac{0.65}{2.12}}+b_{\frac{0.65}{2.12}}, \\
& \rho_{0.47}^{s}=\rho_{0.65}^{s} \cdot M_{\frac{0.47}{0.67}}+b_{\frac{0.47}{0.67}},
\end{aligned}
$$


Table 2. Regression coefficients for the new surface scheme introduced in C6U MDT algorithm.

\begin{tabular}{lrrrr}
\hline & $\begin{array}{r}\mathrm{NDVI}_{\text {SWIR }}<0.2 \\
\text { and UP }>50 \%\end{array}$ & $\begin{array}{r}\mathrm{NDVI}_{\text {SWIR }}<0.2 \\
\text { and } 20 \%<\mathrm{UP} \leq 0 \%\end{array}$ & $\begin{array}{r}\mathrm{NDVI}_{\text {SWIR }}>0.2 \\
\text { and } 20 \%<\mathrm{UP} \leq 70 \%\end{array}$ & $\begin{array}{r}\mathrm{NDVI}_{\text {SWIR }}>0.2 \\
\text { and UP }>70 \%\end{array}$ \\
\hline slope $_{0.65 / 2.12}$ & 0.66 & 0.78 & 0.62 & 0.65 \\
yint $_{0.65 / 2.12}$ & 0.02 & -0.02 & 0.00 & 0.00 \\
slope $_{0.47 / 0.65}$ & 0.52 & 0.51 & 0.47 & 0.48 \\
yint $_{0.47 / 0.65}$ & 0.00 & 0.00 & 0.01 & 0.01 \\
$R_{0.65 / 2.12}$ & 0.91 & 0.92 & 0.91 & 0.86 \\
bbsStd $_{0.65 / 2.12}$ & 0.013 & 0.013 & 0.008 & 0.008 \\
$R_{0.47 / 0.65}$ & 0.96 & 0.95 & 0.88 & 0.81 \\
AbsStd $_{0.47 / 0.65}$ & 0.003 & 0.003 & 0.004 & 0.006 \\
\hline
\end{tabular}

where

$$
\begin{aligned}
& M_{0.65 / 2.12}=\operatorname{slope}_{0.65 / 2.12}^{(\mathrm{NDVI}, \mathrm{UP})}+0.002 \cdot \theta-0.27, \\
& b_{0.65 / 2.12}=\mathrm{yint}_{0.65 / 2.12}^{(\mathrm{NDVI}, \mathrm{UP})}-0.00025 \cdot \theta-0.033 \text {, } \\
& M_{0.47 / 0.67}=\operatorname{slope}_{0.47 / 0.67}^{(\mathrm{NDVI}, \mathrm{UP})} \text {, and } \\
& b_{0.47 / 0.67}=\operatorname{yint}_{0.47 / 0.67}^{(\text {NDVI, UP) }} \text {. }
\end{aligned}
$$

Slope and yint are the regression constants for particular wavelengths, NDVI $\mathrm{SWIR}_{\text {and }}$ UP, found in Table 2.

As shown in Table 2, the new slopes of SWIR-VIS over urban areas are significantly higher than those assumed in the C6 algorithm for global application, which is consistent with other studies (i.e., Levy et al., 2007b; de Almeida Castanho et al., 2007). The red-SWIR ratios are also higher for lessvegetated areas $\left(\mathrm{NDVI}_{\mathrm{SWIR}}<0.2\right)$ than for more-vegetated areas $\left(\right.$ NDVI $\left._{\text {SWIR }}>0.2\right)$.

The new surface scheme is expected to provide better surface reflectance estimates over urban areas than the existing operational scheme (i.e., C6). Figure 2 shows very tight relationships between SWIR-VIS reflectances, but even the presence of the small amount of scatter in the correlation can cause errors in certain conditions and seasons. Bidirectional reflectance function (BRDF) effects over urban surfaces and other factors as discussed in Levy et al. (2007b) may also introduce error. Because surface reflectance dominates the TOA signal for low aerosol conditions $(\mathrm{AOD}<0.1)$ as compared to high aerosol loading (AOD $>0.4$ ), relative uncertainties in retrieving AOD are larger under clean conditions.

UP is the only new parameter added to the surface scheme. This is a globally available parameter calculated from a standard MODIS Land Product (MCD12Q1) and is updated annually. The C6U algorithm inputs UP and uses this parameter to decide whether to apply the old or the new surface parameterization. Dependence on UP assures that there will be no changes to the retrieved aerosol products for non-urban surfaces (UP $<20 \%)$.

We have developed this surface scheme using data from the continental USA, expecting the scheme to be optimized for this region. Global implementation may be challenging and we discuss these challenges in Sect. 6. Also, we note that this application of UP surface correction is applied only for the MODIS $10 \mathrm{~km}$ aerosol product. We discuss future application to $3 \mathrm{~km}$ retrieval in Sect. 6 .

\section{Evaluation of $\mathrm{C6U}$ retrieval}

\subsection{Collocation and analysis strategies}

The data from MODIS Aqua from 2003 to 2012 over the CONUS region are processed using the $\mathrm{C} 6 \mathrm{U}$ algorithm and compared against C6 retrievals and AERONET measurements. MODIS C6 and C6U AODs were collocated over AERONET sites in the CONUS region, using the same spatiotemporal technique (Ichoku et al., 2002) used for MODIS validation exercises (Levy et al., 2010). In this method, AOD values from all the pixels within a $0.5 \times 0.5^{\circ}$ latitudelongitude box centered over the AERONET location are averaged. This is equivalent to approximately a $50 \times 50 \mathrm{~km}^{2}$ area or $5 \times 5$ pixels selection criteria as suggested by Ichoku et al. (2002) and used by Levy et al. (2010). To represent the same air mass for the comparison, AERONET AODs were averaged over $\pm 0.5 \mathrm{~h}$ centered at the satellite overpass time over a particular AERONET station. As recommended by the MODIS science team (Levy et al., 2010, 2013) only AOD pixels with quality flag "very good" were included in the spatial average except when otherwise mentioned. Since we are attempting to differentiate C6U vs. AERONET from C6 vs. AERONET, exactly the same MODIS AOD retrieval squares from the two algorithms were used in the averaging during the collocation with AERONET. To be consistent with previous validation exercises (Levy et al., 2010), we have retained the collocated data sets only when there were at least five MODIS AOD retrievals (out of a possible 25) and two AERONET measurements (out of 2-4) available from the collocation. The C6-C6U-AERONET collocated validation data set consists of 14402 collocations from 134 AERONET stations. For the purpose of evaluation and comparison, the S-MDT version has been used and only collocated pixels are processed. In order to analyze the validation results and un- 
certainties, the following statistical parameters were calculated (Hyer et al., 2011).

Root mean square error (RMSE) and mean bias is estimated using Eqs. (4) and 5.

$\mathrm{RMSE}=\sqrt{\frac{1}{n} \sum\left(\mathrm{AOD}_{\mathrm{AERO}}-\mathrm{AOD}_{\mathrm{MODIS}}\right)^{2}}$

Bias $=$ arithmatic mean $\left(\mathrm{AOD}_{\mathrm{MODIS}}-\mathrm{AOD}_{\mathrm{AERO}}\right)$

Expected error (EE) (Remer et al., 2005) for AOD retrieved over land, as given by the MODIS science team through validation exercises, is presented in Eq. (6).

$\mathrm{EE}= \pm(0.05 \pm 15 \%)$

The percentage of retrievals, falling within the envelope of EE, as compared to AERONET AODs is given by Eq. (7).

$\mathrm{EE} \%=\mathrm{AOD}_{\mathrm{AERO}}-|\mathrm{EE}| \leq \mathrm{AOD}_{\mathrm{MODIS}} \leq \mathrm{AOD}_{\mathrm{AERO}}+|\mathrm{EE}|$,

where the $\mathrm{AOD}_{\mathrm{AERO}}$ is AOD from AERONET, and AOD $_{\text {MODIS }}$ is the retrieved value from MODIS (either C6 or C6U version). Note that the MODIS AOD is reported at $0.55 \mu \mathrm{m}$, so we perform interpolation (quadratic on log-log scale) on the AERONET data.

In addition, we have computed linear regression statistics, including correlation coefficient $(R)$, regression coefficients (slope and intercepts) and number of data points $(N)$.

Note that MODIS also reports AOD values at 0.47 and $0.67 \mu \mathrm{m}$ wavelengths, but these are not independent pieces of information and are determined by the retrieval solution. The spectral dependence of the retrieval (e.g., Ångström exponent) is interesting, but we choose not to validate it in this study.

\subsection{Validation: comparison with AERONET/DRAGON}

Figure 3 shows 2-D density scatter plots, representing all collocations of MODIS-retrieved AOD and AERONET SP measured AOD over CONUS urban sites. Here, only retrievals where UP $>20 \%$ and the retrieval quality assurance flag indicates "very good quality" ( $\mathrm{QAF}=3$; Levy et al., 2014) are shown. Figure 3 (left panel) represents the MODIS C6 retrieval, whereas Fig. 3 (right panel) shows the same collocations but for C6U retrievals. Figure 3 (left panel) clearly shows positive bias (0.07) in C6-retrieved AODs as compared to SP AODs. The bias is significantly reduced (to -0.01 ) when the C6U retrieval is applied (right panel).

As discussed in Sect. 4, aerosol retrieval from passive satellite measurements is sensitive to underlying surface reflectance; the relative uncertainty becomes greater for lower AOD conditions, when the surface reflectance dominates the signal. By improving the overall urban surface reflectance parameterization, the bias is reduced. However, the small negative bias indicates that there is still uncertainty in estimating visible reflectance. We note that most of the negative
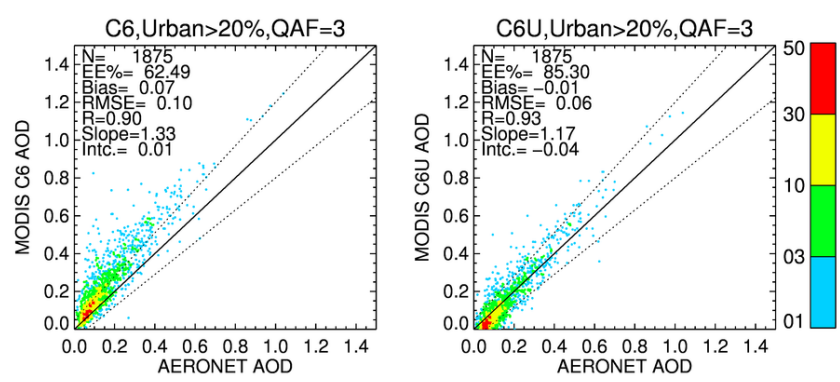

Figure 3. The frequency scatter plot for AOD at $0.55 \mu \mathrm{m}$ over AERONET locations in the CONUS region. This comparison between MODIS and AERONET considers only MODIS AOD pixels with UP larger than $20 \%$ with $\mathrm{QAF}=3$. The side-by-side scatter plots of C6 (left) and C6U (right) AOD retrievals with AERONET are shown to analyze the impact of the new surface scheme on the retrieved AOD values. The one-to-one lines and EE \% envelopes are plotted as solid and dashed lines. The statistics of MODISAERONET comparisons are presented in the top left corner of each scatter plot.

AODs from the C6U retrieval are correctly identifying low values of AODs $(<0.1)$, such that a retrieval of "clean" conditions is correct. The other source of uncertainty in AOD retrievals comes from selection of proper aerosol model, but this effect should be minimal at such low optical depths. The number of retrievals within pre-defined expected error envelope (EE \%) has also increased from $63 \%$ for C6 to $85 \%$ for the C6U retrievals. Most of the statistical parameters in comparing MODIS and SP AODs demonstrate improvement in C6U AODs as compared to C6 retrievals.

Previous validation and inter-comparison studies (Munchak et al., 2013) have pointed out the positive correlation of C6 AOD biases with respect to urban land cover amount. The C6U surface characterization accounts for change in urban area within each MODIS AOD pixel, such that the positive correlation should be reduced in our data set. We would expect that for UP $>20 \%$ the bias should be flat with respect to UP if the new parameterization is doing its job. Figure 4 shows bias in MODIS AOD (MODIS-AERONET) as a function of change in the UP. Again side-by-side comparisons for C6 in Fig. 4a and C6U in the Fig. 4b are presented. Here, we have considered all AOD pixels irrespective of urban percentage, which is different from the source of Fig. 3, which limited us to cases with UP larger than $20 \%$. Here the objective is to evaluate the impact of new surface scheme on the quality of the MDT-retrieved AODs as a whole, beyond urban areas. We recall that the new surface scheme is applied only on selective pixels (UP>20\%), which consist of only about $3 \%$ of the total retrieved AODs in the CONUS region. Red dots show the equal number of points bin averaged value with 1 standard deviation in AOD error as vertical blue line. The biases in C6 AODs linearly increase as land cover becomes more urbanized (larger UP), whereas biases in C6U AODs do not show significant dependence on UP. This anal- 

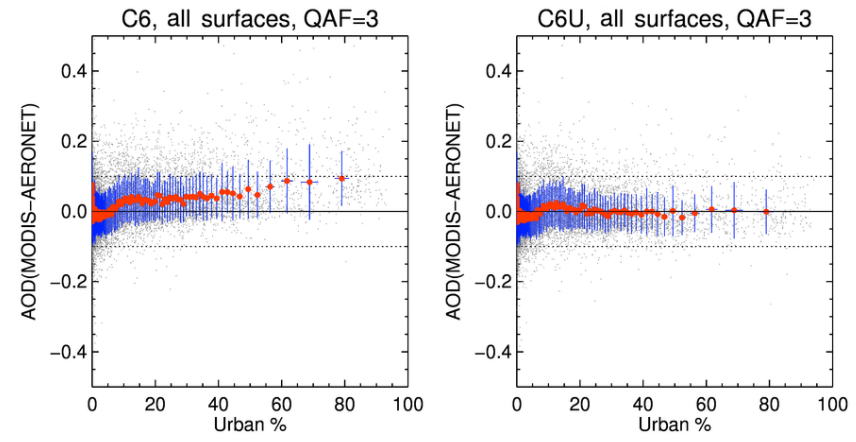

Figure 4. Binned bias in MODIS AODs compared to AERONET AODs as a function of UP, using all collocated data sets with $\mathrm{QAF}=3$. MODIS C6 retrievals on left and MODIS C6U retrievals on the right. Each bin represents 100 points and the error bars are \pm 1 standard deviation in both directions. There are a total of 14402 MODIS-AERONET collocated points compared in the plot. C6 AODs show increased in bias over urbanized land surfaces whereas $\mathrm{C} 6 \mathrm{U}$ is able to correct the bias over the CONUS region for $\mathrm{QAF}=3$ data points.

ysis indicates that the C6U surface parameterization successfully removes AOD biases over cities and should be applied to MDT aerosol retrievals over the CONUS region.

The MODIS AOD data presented in Figs. 3 and 4 represent collocations for where the quality assurance flag identifies the retrieval as "science quality" $(\mathrm{QAF}=3$, "very good"; Levy et al., 2013). A QAF value is defined for each MODIS AOD pixel based on retrieving conditions (i.e., number of available cloud-free pixels, presence of cirrus cloud, surface reflectance, retrieving error) as reported in Levy et al. (2013). AOD retrievals with QAF of 3, 2, 1 and 0 are considered as "very good", "good", "marginal" and "poor", respectively. Further details on the QAF can be found in Levy et al. (2013). For some applications, including identifying large aerosol "events", there is interest in analyzing retrievals with lower, but non-zero values of confidence flags (QAF $>0$ ). For example, for air-quality interest, it would be useful to identify heavy aerosol loading, even within cloud fields.

In order to analyze and validate MODIS AODs with lower quality flags, we have grouped the data in several different ways to represent different retrieval conditions. Table 3 presents the statistical analysis of the two retrievals (C6 and $\mathrm{C6U})$ for three categories of underlying surface type (i.e., UP). These are

1. ALL: all retrievals irrespective of UP;

2. UP $>0.0 \%$ : retrievals that have some urban fraction;

3. UP > $20 \%$ : retrievals with UP larger than $20 \%$.

For the third category (UP>20\%), this includes only retrievals where C6U retrieval would be applied and different from C6, while the second category includes retrievals that may be suburbs or small towns, and the first category (ALL) includes everything.

Since QAF value is most strongly connected to the number of pixels used in the retrieval, the difference between C6U and C6 would not be reflected in reported QAF value.

Each surface category in Table 3 is further broken down by QAF level. Note that the case of ALL and QAF $=3$ represents the data in Fig. 4, which are the MDT recommendations of "science-quality" data. The correlation for C6U ( $R=0.86)$ is marginally higher than for C6 $(R=0.85)$, but the bias is reduced to 0.006 from 0.022 . The number of retrievals within EE \% increased by $4 \%$. For the UP> $20 \%$ cases (e.g., data shown in Fig. 3), there is a huge reduction in bias (from 0.075 to -0.007 ), and the EE \% increases from 58.6 to $85.3 \%$.

For the C6 data, there is a clear reduction in regression quality (decreased correlation, increased bias, \%EE reduction) as QAF criteria are relaxed from 3 to 2 to 1 . This is true for the set of ALL retrievals, but especially when the retrieval is performed over even a small fraction of urban surface type (UP>0). For C6U, the immediate effect is to cut bias to a negligible value for $\mathrm{QAF}=3$ for all categories including ALL. As QAF criteria are relaxed, bias jumps up and correlation and EE \% decrease, although not as drastically as for the $\mathrm{C} 6$ retrievals. In fact, the statistics, including bias, for the $\mathrm{QAF}=2$ or 3 criteria are not much different than the statistics for the current $\mathrm{C} 6$ retrievals for $\mathrm{QAF}=3$ only. However, there is improved sampling (50\% more collocations with AERONET). If the currently recommended C6 retrieval at $\mathrm{QAF}=3$ is adequate, then it may make sense to recommend $\mathrm{QAF}=2$ and 3 for the $\mathrm{C} 6 \mathrm{U}$ algorithm and increase the number of available retrievals by 30,50 and $84 \%$ for ALL, UP $>0$ and UP $>20 \%$ categories, respectively.

The improved statistics for AOD retrievals with lower assigned quality flags are encouraging and suggest opportunity for overall increase in high-quality sampling with the MDT algorithm. This will definitely help characterize aerosol for air-quality applications in densely populated areas. However, further research and dedicated evaluations of quality flag assignment criteria in the algorithm are required before we suggest making use of lower-quality data even in the C6U retrievals.

\subsection{Evaluation over selected cities}

The main reason for the development of the C6U retrieval algorithm is to reduce the biases in AOD retrievals over cities where a large portion of the human populations lives. In this section, we evaluate both $\mathrm{C} 6$ and $\mathrm{C} 6 \mathrm{U}$ retrievals over selected cities where an AERONET station is available. Figure 5 shows how C6 (red dots) and C6U (blue dots) compare with AERONET AODs over eight selected AERONET stations covering various parts of CONUS and Canada. Only MODIS AOD retrievals with $\mathrm{QAF}=3$ are considered for this analysis. These selected AERONET stations are marked (circles) 
Table 3. Statistics of MODIS and AERONET inter-comparisons using collocated data sets. Comparisons are performed for different quality flags. Three different MODIS pixel selection schemes based on surface type are used. All: all MODIS pixels were considered irrespective of underlying surface type; urban \% >0.0: MODIS pixels with urban surface were selected; urban \% $>20$ : MODIS pixels with urban percentage larger than $20 \%$ were selected in collocation. Statistical parameters, number of data points $(N)$ linear correlation coefficient $(R)$, mean bias (bias) and $\mathrm{EE} \%$ are reported in this table.

\begin{tabular}{lrrrrrrrr}
\hline & \multicolumn{2}{c}{$R$} & \multicolumn{2}{c}{ Bias } & EE \% \\
\hline Data Set & QAF & $N$ & C6 & C6U & C6 & C6U & C6 & C6U \\
\hline All & 1 & 723 & 0.67 & 0.74 & 0.114 & 0.072 & 38.8 & 52.6 \\
& 1,2 & 6415 & 0.73 & 0.78 & 0.106 & 0.067 & 41.9 & 56.4 \\
& $1,2,3$ & 21842 & 0.80 & 0.83 & 0.051 & 0.029 & 65.0 & 72.5 \\
& 2,3 & 18995 & 0.81 & 0.84 & 0.041 & 0.020 & 69.1 & 76.0 \\
& 3 & 14402 & 0.85 & 0.86 & 0.022 & 0.006 & 77.1 & 81.1 \\
\hline Urban \%>0.0 & 1 & 295 & 0.63 & 0.74 & 0.171 & 0.084 & 27.3 & 55.0 \\
& 1,2 & 3269 & 0.68 & 0.77 & 0.141 & 0.070 & 31.3 & 57.5 \\
& $1,2,3$ & 11258 & 0.78 & 0.84 & 0.071 & 0.028 & 59.1 & 74.6 \\
& 2,3 & 9455 & 0.79 & 0.85 & 0.062 & 0.020 & 63.8 & 78.1 \\
& 3 & 6300 & 0.88 & 0.90 & 0.036 & 0.002 & 75.2 & 85.2 \\
\hline Urban \%>20.0 & 1 & 109 & 0.50 & 0.59 & 0.259 & 0.105 & 15.5 & 49.5 \\
& 1,2 & 1406 & 0.65 & 0.73 & 0.205 & 0.083 & 16.6 & 52.0 \\
& $1,2,3$ & 4301 & 0.75 & 0.83 & 0.128 & 0.032 & 37.4 & 73.2 \\
& 2,3 & 3451 & 0.78 & 0.85 & 0.115 & 0.021 & 42.2 & 76.8 \\
& 3 & 1875 & 0.90 & 0.93 & 0.075 & -0.007 & 58.6 & 85.3 \\
\hline
\end{tabular}

Table 4. Statistics of MODIS and AERONET inter-comparisons over selected urban sites (Fig. 5). Statistical parameters are the number of coincident points $(N)$, linear Correlation coefficient $(R)$, percentage of retrievals with uncertainty envelope (EE \%), root mean square error (RMSE), mean bias (Bias), slope and intercepts.

\begin{tabular}{lrrrrrrrr}
\hline AERONET Station & Version & $N$ & $R$ & EE \% & RMSE & Bias & Slope & Intercept \\
\hline Toronto & C6 & 222 & 0.92 & 78.83 & 0.08 & 0.04 & 1.28 & -0.01 \\
& C6U & 222 & 0.94 & 89.64 & 0.06 & 0.01 & 1.20 & -0.02 \\
\hline CCNY & C6 & 173 & 0.94 & 46.24 & 0.12 & 0.09 & 1.21 & 0.05 \\
& C6U & 173 & 0.95 & 83.24 & 0.07 & 0.00 & 1.15 & -0.03 \\
\hline MD_Science_Center & C6 & 354 & 0.95 & 85.88 & 0.06 & 0.02 & 1.26 & -0.01 \\
& C6U & 354 & 0.95 & 88.70 & 0.05 & -0.02 & 1.18 & -0.04 \\
\hline GSFC & C6 & 650 & 0.96 & 83.23 & 0.06 & 0.03 & 1.30 & -0.01 \\
& C6U & 650 & 0.96 & 92.46 & 0.05 & -0.01 & 1.18 & -0.03 \\
\hline BSRN_BAO_Boulder & C6 & 571 & 0.91 & 66.90 & 0.08 & 0.05 & 1.29 & 0.02 \\
& C6U & 571 & 0.92 & 83.01 & 0.06 & 0.03 & 1.25 & 0.00 \\
\hline Univ_of_Houston & C6 & 119 & 0.93 & 83.19 & 0.05 & 0.03 & 1.29 & 0.00 \\
& C6U & 119 & 0.93 & 94.96 & 0.03 & -0.01 & 1.05 & -0.02 \\
\hline Caltech & C6 & 165 & 0.42 & 51.52 & 0.13 & 0.06 & 0.76 & 0.08 \\
& C6U & 165 & 0.58 & 69.70 & 0.08 & 0.00 & 0.84 & 0.02 \\
\hline Fresno & C6 & 910 & 0.81 & 87.80 & 0.05 & 0.00 & 0.94 & 0.01 \\
& C6U & 910 & 0.81 & 88.24 & 0.05 & -0.01 & 0.94 & 0.00 \\
\hline
\end{tabular}

in Fig. 1. Table 4 provides statistical parameters corresponding to the scatter plots presented in Fig. 5. All AERONET stations show positive bias in C6 AOD, which, except for Fresno, is corrected in the C6U retrievals. Over Fresno, the two retrievals have similar bias, which was near zero to begin with. Both retrievals have high correlations $(>0.9)$ with AERONET over all stations except the western US stations. 

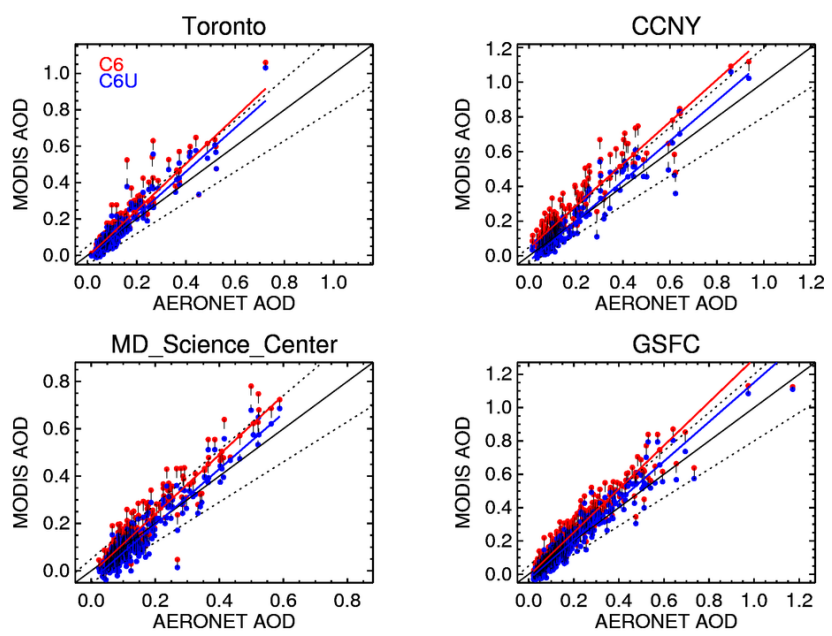

Univ_of_Houston

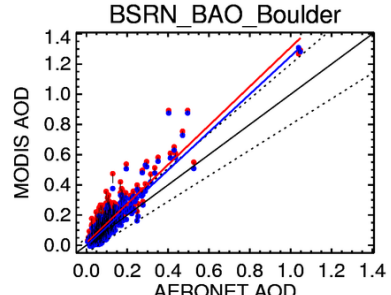

CalTech

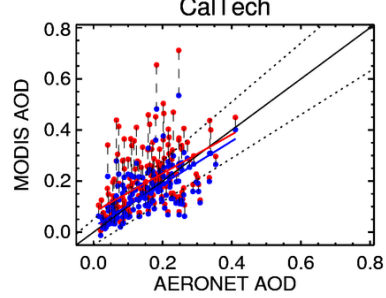

observed over the New York City (CCNY) AERONET station. The number of retrievals within the uncertainty window (EE \%) at CCNY almost doubled from $46 \%$ in $\mathrm{C} 6$ to $83 \%$ in $\mathrm{C} 6 \mathrm{U}$, and the bias is reduced to 0 from 0.09 . The $\mathrm{C} 6 \mathrm{U}$ results over CCNY observed a slight negative offset of -0.03 mainly due to a negative bias in low aerosol loading conditions $(\mathrm{AOD}<0.1)$. In general the slope is larger than one for eastern US sites whereas it less than one for western US sites.

In Fig. 6 we have evaluated the spatial distribution of AOD over the region covering two large urban cities, Baltimore and Washington DC. The map shows averaged AODs for the period of June-August 2011. The main purpose of the figure is to demonstrate, spatially, that the $\mathrm{C} 6 \mathrm{U}$ algorithm reduces the high AOD bias over urban surfaces, such as the Washington DC area in the figure. There we see that the seasonal mean values in the $\mathrm{C} 6 \mathrm{U}$ algorithm are more spatially consistent with the surrounding suburban and rural area than are the values from C6. Figure $6 \mathrm{c}$ shows the difference between C6 and C6U AODs, which is correlated with UP (Fig. 6d) and could be as high as 0.12 .

The secondary purpose of the figure is to demonstrate that the C6U algorithm has not solved all problems associated with the retrieval over cities. There are still artificially high seasonal mean values for Baltimore and the Chesapeake Bay shoreline. The reason these seasonal mean values remain artificially inflated is because of sampling. Figure 6e presents the number of averaging days (or number of retrievals) for each grid box, and it is apparent that some grids near city centers and along the shoreline have very limited sampling (1-5) days. Coincidently, these available days correspond to high aerosol loading days, creating an illusion of high seasonal mean aerosol loading in the city centers and along the Chesapeake Bay. The low number of retrievals in these squares is caused by a combination of clouds and the additional issue of the algorithm choosing not to retrieve over very bright urban surfaces under low aerosol loading and at certain sun-satellite geometry. While the new C6U algorithm will be able to produce a better urban retrieval when an urban pixel is selected for processing, it will continue to be affected by the algorithm's pixel selection process that makes it difficult for urban pixels to be chosen. This work focuses on the parameterization of the surface reflectance relationships and not on the upstream pixel selection and masking processes.

\subsection{Regional analysis over DRAGONs}

Figure 7a-h show the evaluation statistics of the two algorithms over a dense network of AERONET instruments in the Baltimore-Washington DC metropolitan area during summer 2011. The DRAGON is a mesoscale network of sun/sky radiometers that encompasses, urban, suburban, agricultural and hilly landscapes over the Washington DC metropolitan area. There were about 39 AERONET DRAGON stations operating during this deployment. This dense SP network provides an excellent aerosol measurements data set covering 


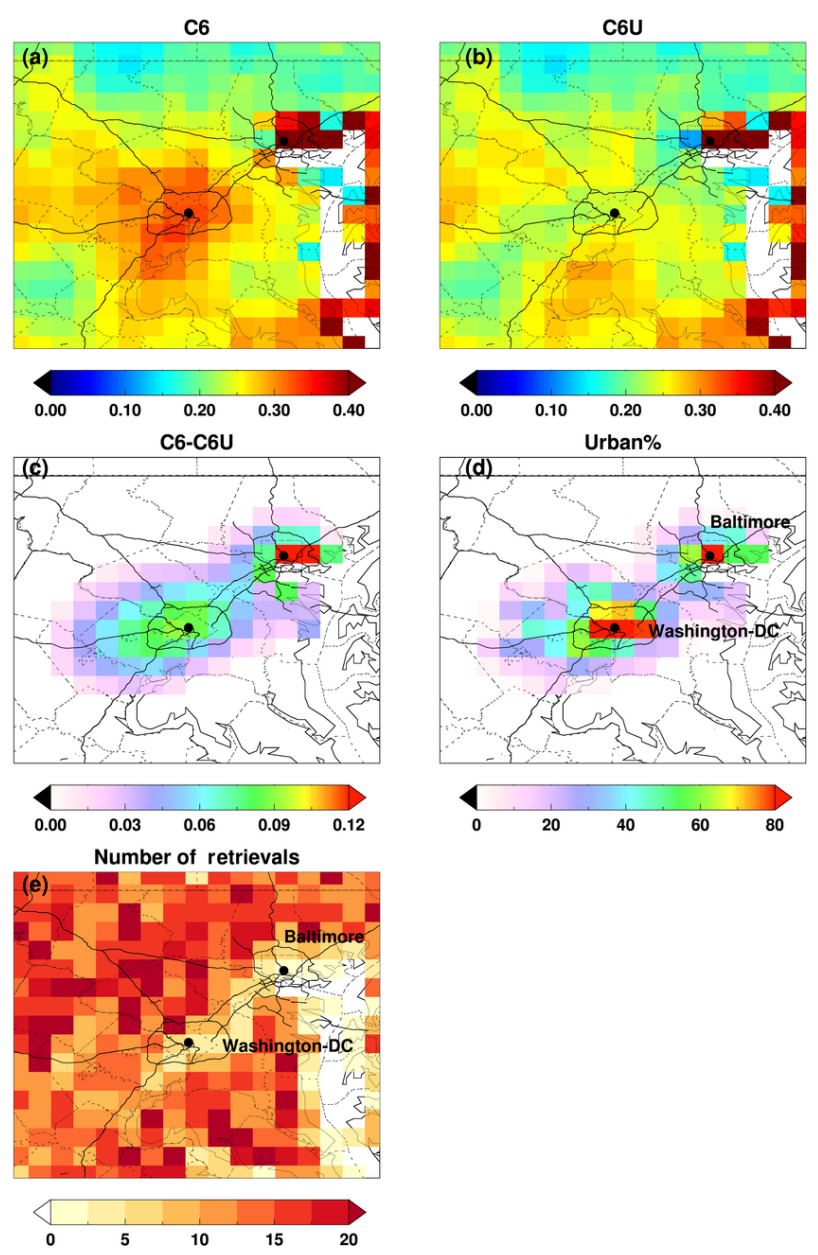

Figure 6. Seasonal (June-July-August 2011) maps of MODIS $\mathrm{AOD}$ at $0.55 \mu \mathrm{m}$ as retrieved by C6 (a), C6U (b), C6-C6U (c) and urban \% (d) covering Washington DC and Baltimore urban corridor. (e) Number of AOD retrievals over the season. MODIS AODs with $\mathrm{QAF}=3$ for 3 months have been averaged over $0.1 \times 0.1^{\circ}$ grids to generate these maps. C6U MDT-retrieved AODs are lower over large cities as compared to C6 AODs, and the improvements are well correlated with UP.

different types of landscapes. This AERONET DRAGON deployment also provides an excellent opportunity to evaluate the high AOD values near the cities as observed in Fig. 6. The data have been utilized to validate satellite aerosol retrievals and spatial variability in the aerosol fields (Munchak et al., 2013). Munchak et al. (2013) reported that the MODIS C6 AOD retrievals were positively biased against AERONET values in (and near) urban areas with a high degree of correlation with UP. We now revisit the Munchak et al. (2013) data sets to verify whether the new C6U retrievals alleviate the issues noted by the previous study.

Figure 7a, c, e, g (left panels) and b, d, f, h (right panels) represent comparisons between MODIS C6 and C6U AOD validation statistics, respectively. The two scatter plots show MODIS-retrieved AOD plotted against AERONET measure-
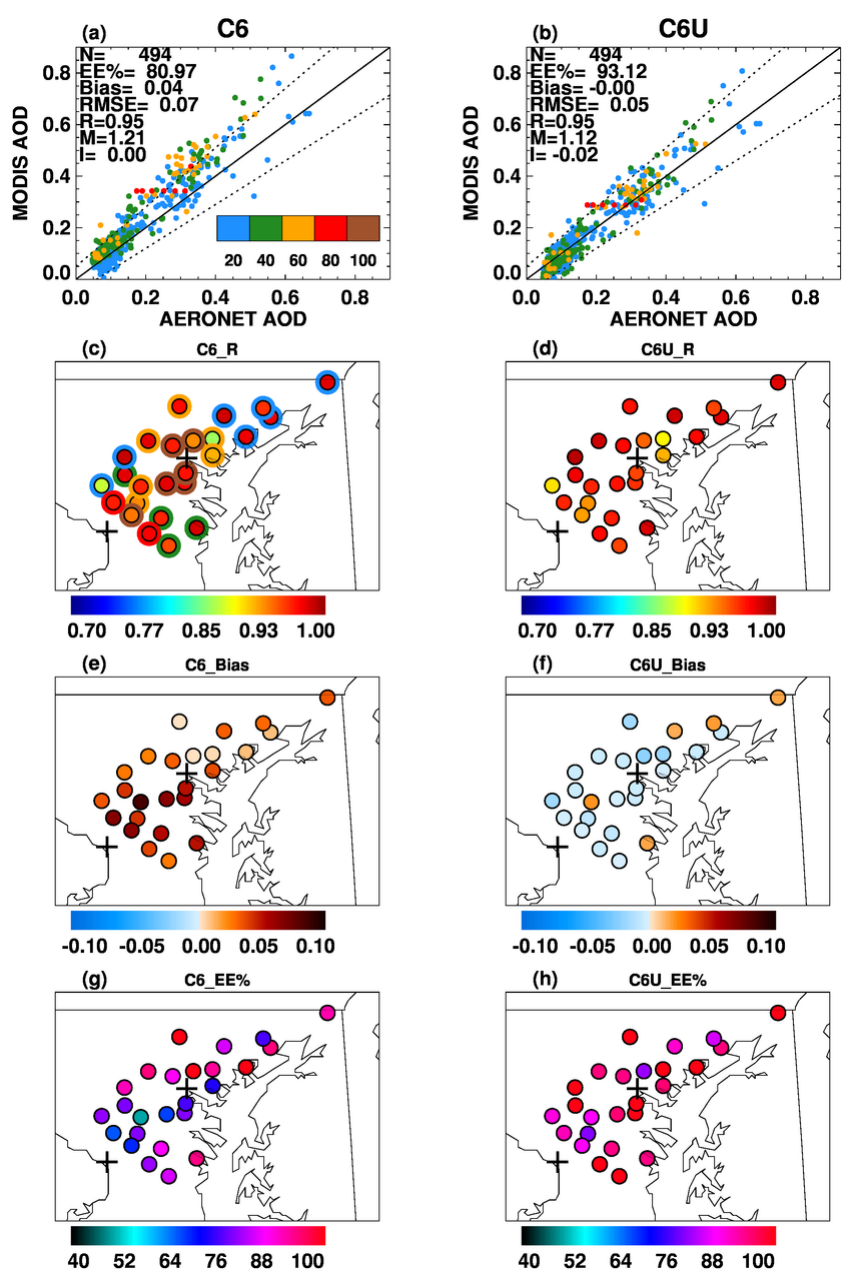

Figure 7. Inter-comparison statistics of MODIS-AERONET AODs over DRAGON network during DISCOVER-AQ field campaign (June-July 2011) in the Washington DC-Baltimore area. This analysis used data from AERONET stations operated as part of DRAGON network. Scatter plot between AERONET and MODIS for C6 (a), C6U (b); each collocated point is color-coded with UP corresponding to AERONET site. Other statistical parameters for each AERONET stations are mapped in following order: (c) linear correlation coefficient $(R)$ for $\mathrm{C6}$ and $\mathrm{UP}$, (d) $R$ for C6U, (e) mean bias in C6 AODs, (f) mean bias in C6U AODs, (g) EE \% from C6 and (h) EE \% from C6U.

ments. Each point is color-coded with the UP estimated for each DRAGON site using the MODIS Land Cover Type information. The C6 AODs show (Fig. 7a) positive biases specifically for AOD values larger than 0.15 , which results in an overall positive bias of 0.04 with very high correlation $(R)$ of 0.95 , suggesting consistent bias in AOD in the C6 retrieval. These statistics are very similar to the Munchak et al. (2013) results where data from both Terra and Aqua MODIS were analyzed. Here only data from MODIS Aqua are included. The UP color-coding hints that most of the positively biased AOD pixels are located in a highly urbanized 
(UP $>60 \%$ ) area. The two scatter plots (Fig. 7a and b) very clearly show the improvement in AOD comparisons against AERONET when the C6U algorithm is applied. The mean bias between MODIS and AERONET is reduced to almost 0 , and EE \% has gone up to $93 \%$. This implies that the RMSE and slope have also improved in the C6U retrievals, as compared with the $\mathrm{C} 6$ retrievals, but the offset $(I)$ in $\mathrm{C} 6 \mathrm{U}$ is now slightly negative $(-0.02)$, which was 0 in the $\mathrm{C} 6$ retrievals. A closer look at the scatter plot reveals that C6U has introduced some negative bias at very low AOD cases (AOD <0.15), which is consistent with previous analysis over the CONUS region. Again, in order to remove these negative biases, more accurate estimation of surface parameters is required. The remaining figures show correlation, bias and EE \% for the two algorithms over individual DRAGON sites. The outer colorcoded circle in Fig. 7c represents UP over each DRAGON site. The color-coding is done according to the scale shown in the Fig. 7a. In almost all statistical parameters, C6U outperformed C6 algorithm over each station.

\section{Global implications and challenges}

The new surface scheme presented here is designed to work only over CONUS (and perhaps other regions with similar surface properties) and with the $10 \mathrm{~km}$ aerosol retrieval. Implementing the new scheme into the global algorithm, as well as at a different spatial resolution (e.g., $3 \mathrm{~km}$ ), may be challenging. In CONUS we had a wealth of data to work with: 135 AERONET stations with several in highly urban locations and a well-analyzed DRAGON network to evaluate the small-scale variability in the aerosol fields. We were able to parameterize the surface reflectance relationships by dividing the surfaces into only four categories depending on

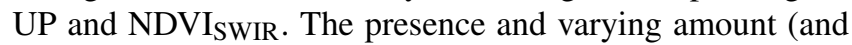
type) of vegetation in the urban areas and the different materials used in construction of buildings and roads in other parts of the world will make accurate surface parameterization a more complex problem. However, because the results over CONUS have been so encouraging, we decided to run the CONUS-derived C6U algorithm globally and to compare the results with AERONET measurements. Figure 8 presents the difference between C6U AOD with AERONET AOD as a function of UP over the entire global data set, excluding AERONET stations from the CONUS region. The CONUS region has been excluded in order to avoid weighting the results by the formulation data set. The results are surprisingly good. The CONUS-derived C6U has reduced the positive bias over urban surfaces to nearly 0 globally. This analysis is very encouraging, but more in depth analysis for specific stations/regions will be required to better understand the new algorithm before applying it operationally at global scale.
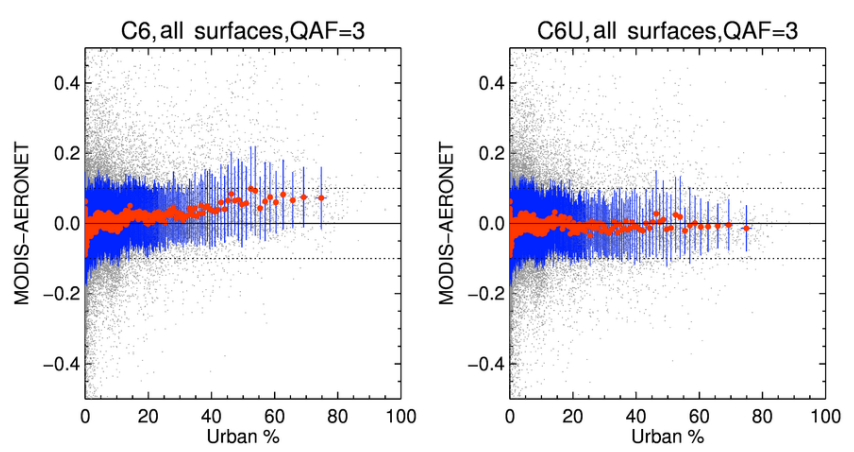

Figure 8. Binned bias in MODIS AODs compared to AERONET AODs as a function of UP using all collocated data sets with $\mathrm{QAF}=3$. This analysis used data from global (excluding CONUS region) AERONET network for the period of January 2003June 2013. MODIS C6 retrievals are on the left and MODIS C6U retrievals are on the right. Each bin represents 100 points and the error bars are \pm 1 standard deviation in both directions. There are a total of 50948 MODIS-AERONET collocated points from 302 stations compared in this plot. C6 AODs show increased in bias over urbanized land surfaces whereas $\mathrm{C} 6 \mathrm{U}$ is able to correct the bias over the region for $\mathrm{QAF}=3$ data points.

\section{Discussion of the MxD09 product from the perspective of this study}

For years the MDT algorithm refrained from using the MxD09 because of the question of "circularity". The MODIS land atmospheric correction and aerosol retrieval algorithms evolved from the same basic root (Vermote et al., 1997; Kaufman et al., 1997). Using the land reflectance derived from the aerosol algorithm to derive the AOD that is used to produce the land reflectance would create an incestuous circular relationship, tuned to agree at AERONET stations and nowhere else. However, over time the land atmospheric correction and the Dark Target aerosol retrieval evolved significantly into very different second-generation algorithms, using a different set of wavelengths, a different set of assumptions of aerosol properties and minimizing a different cost function in the inversion (Vermote and Kotchenova, 2008; Levy et al., $2007 \mathrm{a}, \mathrm{b})$. To reduce the possible circularity even further, we do not attempt to directly use daily surface reflectance product in our MDT algorithm but rather look for spectral relationships. Mirroring the logic within the C6 MDT algorithm, we use 1 year of MOD09 over CONUS to form the SWIRVIS relationships as a function of NDVI $_{\text {SWIR }}$ and urban percent. Therefore no direct use of surface reflectance product is used for our urban DT retrieval.

The next question concerns the uncertainty in the MxD09 described above in Sect. 3.3. The MxD09 algorithm attempts to match the atmospherically corrected surface reflectance ratios with pre-determined values by adjusting simultaneously the AOD and surface reflectance. The predetermined surface reflectance ratios are derived from a 
global database of atmospherically corrected surface reflectance at AERONET sites. There is one global value per pair of wavelengths. Because, as we have shown, the surface reflectance ratios over urban surfaces differ from the vast majority of land surface types, we would expect that MxD09 values over urban surfaces to show higher errors and greater uncertainty than more rural and typical surfaces. Indeed that is the case as shown in Sect. 3.3. If this error is not spectrally uniform and involves a bias as well as random error, as is suggested by the urban example in Vermote and Kotchenova (2008), then the ratios that we derive from MxD09 in Fig. 2 will not represent that actual surface reflectances in the MDT retrieval. Errors and biases will be introduced into the C6U results. Comparisons against AERONET will be partially contaminated because the original MxD09 predetermined surface reflectance ratios were based on the corrected surface reflectances surrounding AERONET sites.

Despite these causes of concern, we proceeded with the use of MxD09 in this study because this is the only data set having robust statistics with any hope of providing surface reflectance ratios in urban settings at the spatial scale needed. Any alternative method of performing our own atmospheric correction at specific AERONET locations with variable UP to determine our own urban surface reflectance ratios would suffer from limited statistics. Our decision to proceed with MxD09 has been justified with the results shown in Figs. 3, 4, 5 and especially 6,7 and 8. The C6U results not only bring the urban AOD closer to the AERONET values in a general sense but also reduce the urban bias beyond the original AERONET stations used to derive the pre-determined surface reflectance ratios. We see this across the DRAGON network of Fig. 7, where C6U brings down the bias and captures the mesoscale variation of the aerosol. None of these DRAGON stations existed at the time that the universal surface reflectance ratios were determined for the MxD09 algorithm, and therefore this is a clean validation. We also note that AERONET has grown significantly since the MxD09 pre-determined ratios were calculated, and while our validation data set may overlap with the formulation one, it is not identical. Figure 8 also bolsters our confidence in this data set. Note that the urban surface reflectance ratios we derive in Fig. 2 were derived using only values over CONUS. There was no guarantee that these values would improve retrievals over non-CONUS cities, but they do.

Thus, while the MxD09 product has significant uncertainty in the blue channel, especially over urban surfaces, that uncertainty appears to be manageable. There is no doubt that $\mathrm{C} 6 \mathrm{U}$ is an improvement over $\mathrm{C} 6$ in urban settings.

\section{Summary and conclusions}

The MDT aerosol retrieval algorithm, shaped by continuing research and influenced by application needs, has been operating successfully for 15 years. The MODIS C6U al- gorithm presented here reflects the MODIS science team's commitment to keeping the algorithm updated and relevant. In this spirit, we address the AOD biases in the current operational product related to improper surface parameterization over urban areas. We develop a revised surface parameterization scheme over urban regions using the MODIS Land Surface Reflectance and Land Cover Type products. The new parameterization parallels the current Collection 6 surface scheme, where visible surface reflectances are estimated for each pixel using the value of the SWIR surface reflectances at that pixel, modified by NDVI new scheme introduces one additional parameter, the percentage of urban land type cover (UP) for each retrieval box. The new surface scheme is only applied for MODIS retrieval boxes with UP larger than $20 \%$. All other MODIS retrievals have been treated exactly same as in the C6 algorithm. Initially, the surface parameterization has been developed and implemented only for the continental United States.

MODIS Aqua data sets from 2003 to 2012 over all AERONET stations in the USA including a dense DRAGON network deployed during the DISCOVER-AQ field campaign in the Baltimore-Washington DC metropolitan area, have been utilized to evaluate the revised AOD retrievals. The side-by-side comparison of $\mathrm{C} 6$ and $\mathrm{C} 6 \mathrm{U}$ retrieval against AERONET measurements provided quantitative estimates of improvements in the MODIS AOD retrievals. Over urban areas where the C6U retrieval has been applied (UP> $20 \%$ ), we find an increase of more than $20 \%$ in the number of retrievals falling within EE \%. The strong positive correlation between bias in AOD and amount of urban surface near the AERONET site that was observed in $\mathrm{C} 6$ is gone in C6U. The C6U retrieval does introduce a small negative bias in the retrieved AOD for AOD values less than 0.1 due to ultrasensitivity of the AOD retrieval to the surface parameterization under low atmospheric aerosol loadings.

While the new C6U algorithm successfully reduces the high biases in AOD seen over urban pixels when one of these pixels is selected for retrieval, C6U does not affect the pixel selection process. Pixel selection itself is affected by the properties of urban surfaces, and under low aerosol loading conditions and certain geometries, urban pixels are disproportionally rejected for retrieval. Thus, $\mathrm{C} 6 \mathrm{U}$ will improve retrievals when retrievals are made but will not increase the number of retrievals attempted.

In general, the MODIS science team recommends using AOD data with the best-quality flag $(\mathrm{QAF}=3)$ for any over land quantitative purpose. However, depending on application and for qualitative purposes, lower-quality flags ( $\mathrm{QA}=1$ and 2) can also be useful. When we explored the effect of including C6U retrievals of lower quality we found a significant reduction of error for lower-quality AOD retrievals. On several occasions, C6U AOD with lower-quality flags were of essentially the same accuracy of those C6 retrievals with best-quality flags. Relaxing the criteria could increase the number of useable retrievals from 30 to $80 \%$. It is too soon 
to change the recommendation and relax the QAF criteria for quantitative purposes, but this analysis definitely gives sufficient motivation to revisit the quality flag assignment scheme in the MODIS DT algorithm if the C6U algorithm is implemented operationally.

While the formulation of the C6U algorithm is based on surface characterization of stations in the continental USA, we tested the new algorithm on the global data set and compared with AERONET AOD. Even when excluding the CONUS AERONET stations to avoid the mistake of validating the formulation data set, the results show the elimination of AOD bias as a function of urban percentage. These are unexpected, but encouraging, results that suggest that the parameterization developed from the CONUS data may be implemented soon into the global operational algorithm for a significant improvement over urban centers worldwide. Additional testing will be necessary first.

As populations flock to urban centers, causing the urban landscape around the world to grow continuously, it becomes obvious that these regions can no longer be treated with second-class status by the MDT aerosol algorithm. It is crucial to have accurate retrievals of AOD over the urban landscape, which translate into more accurate estimates of particulate matter concentrations for air-quality purposes over the regions where most people live. The revised C6U algorithm improves the quality of MODIS AOD retrievals over urban regions, which will be extremely useful for air-quality applications. We expect that this improvement will open up new opportunities for the research community to apply the MDT AOD data to address other pressing issues such as urbanscale spatial variability, gradients between rural and urban areas, more accurate long-term trends and air-quality-health links.

Acknowledgements. AERONET data were obtained from the NASA AERONET data server; we would like to thank the AERONET team for maintaining the network and data archive. We could not do this study without the AERONET and DRAGON teams' continuing support of quality-controlled, easy-access data. This project is supported through NASA ROSES grants under Terra-Aqua: NNH13ZDA001N-TERAQEA MODIS maintenance project.

Edited by: M. Wendisch

Reviewed by: two anonymous referees

\section{References}

Cooper, M., Martin, R. V., van Donkelaar, A., Lamsal, L., Brauer, M., and Brook, J.: A satellite-based multi-pollutant index of global air quality, Env. Sci. and Tech., 46, 8523-8524, 2012.

de Almeida Castanho, A. D., Prinn, R., Martins, V., Herold, M., Ichoku, C., and Molina, L. T.: Analysis of Visible/SWIR surface reflectance ratios for aerosol retrievals from satellite in
Mexico City urban area, Atmos. Chem. Phys., 7, 5467-5477, doi:10.5194/acp-7-5467-2007, 2007.

de Almeida Castanho, A. D., Vanderlei Martins, J., and Artaxo, P.: MODIS Aerosol Optical Depth Retrievals with high spatial resolution over an Urban Area using the Critical Reflectance, J. Geophys. Res., 113, D02201, doi:10.1029/2007JD008751, 2008.

Eck, T. F., Holben, B. N., Reid, J. S., Dubovik, O., Smirnov, A., O'Neill, N. T., et al.: Wavelength dependence of the optical depth of biomass burning, urban, and desert dust aerosols, J. Geophys. Res.-Atmos., 104, 31333-31349, 1999.

Escribano, J., Gallardo, L., Rondanelli, R., and Choi, Y.-S.: Satellite retrievals of aerosol optical 10 depth over a subtropical urban area: the role of stratification and surface reflectance, Aerosol Air Qual. Res., 14, 596-U568, doi:10.4209/aaqr.2013.03.0082, 2014.

Friedl, M. A., Sulla-Menashe, D., Tan, B., Schneider, A., Ramankutty, N., Sibley, A., and Huang, X.: MODIS Collection 5 global land cover: Algorithm refinements and characterization of new datasets, Remote Sens. Environ., 114, 168-182, 2010.

Gupta, P. and Christopher, S. A.: Particulate matter air quality assessment using integrated surface, satellite, and meteorological products: Multiple regression approach, J. Geophys. Res., 114, D14205, doi:10.1029/2008JD011496, 2009.

Gupta, P., Christopher, S. A., Wang, J., Gehrig, R., Lee, Y., and Kumar, N.: Satellite remote sensing of particulate matter and air quality assessment over global cities, Atmos. Environ., 40, 5880 5892, 2006.

Gupta, P., Khan, M. N; da Silva, A; Patadia, F.: MODIS aerosol optical depth observations over urban areas in Pakistan: quantity and quality of the data for air quality monitoring, Atmospheric Pollution Research, 4, 43-52, 2013.

Hoff, R. M. and Christopher, S. A.: Remote sensing of particulate pollution from space: have we reached the promised land?, J. Air Waste Manage., 59, 645-675, 2009.

Holben, B. N., Eck, T. F., Slutsker, I., Tanre, D., Buis, J. P., Setzer, A., Vermote, E., Reagan, J. A., Kaufman, Y., Nakajima, T., Lavenu, F., Jankowiak, I., and Smirnov A.: AERONET - A federated instrument network and data archive for aerosol characterization, Remote Sens. Environ., 66, 1-16, 1998.

Holben, B., Eck, T., Schafer, J., Giles, D., and Mikhail, M.: Distributed Regional Aerosol Gridded Observation Networks (DRAGON), White Paper, NASA Goddard Space Flight Center, p. 13, 2011.

Hyer, E. J., Reid, J. S., and Zhang, J.: An over-land aerosol optical depth data set for data assimilation by filtering, correction, and aggregation of MODIS Collection 5 optical depth retrievals, Atmos. Meas. Tech., 4, 379-408, doi:10.5194/amt-4-379-2011, 2011.

Ichoku, C., Chu, D. A., Mattoo, S., Kaufman, Y. J., Remer, L. A., Tanre, D., Slutsker, I., and Holben, B. N.: A spatiotemporal approach for global validation and analysis of MODIS aerosol products, Geophys. Res. Lett., 29, MOD1.1-MOD1.4, doi:10.1029/2001GL013206, 2002.

IPCC, 2007: Climate Change 2007: The Physical Science Basis. Contribution of Working Group I to the Fourth Assessment Report of the Intergovernmental Panel on Climate Change, edited by: Solomon, S., Qin, D., Manning, M., Chen, Z., Marquis, M., Averyt, K. B., Tignor, M., and Miller, H. L., Cambridge Uni- 
versity Press, Cambridge, United Kingdom and New York, NY, USA, 2007.

Jäkel, E., Mey, B., Levy, R., Gu, X., Yu, T., Li, Z., Althausen, D., Heese, B., and Wendisch, M.: Adaption of the MODIS aerosol retrieval algorithm using airborne spectral surface reflectance measurements over urban areas: a case study, Atmos. Meas. Tech., 8, 5237-5249, doi:10.5194/amt-8-5237-2015, 2015.

Jethva, H., Satheesh, S. K., and Srinivasan, J.: Assessment of second-generation MODIS aerosol retrieval (Collection 005) at Kanpur, India, Geophys. Res. Lett., 34, L19802, doi:10.1029/2007GL029647, 2007.

Kaufman, Y. J., Tanré, D., Gordon, H. R., Nakajima, T., Lenoble, J., Frouin, R., Grassl, H., Herman, B. M., King, M. D., and Teillet, P. M.: Passive remote sensing of tropospheric aerosol and atmospheric correction for the aerosol effects, J. Geophys. Res., 102, 16815-16830, 1997a.

Kaufman, Y. J., Tanre, D., Remer, L., Vermote, E., Chu, A., and Holben, B. N.: Operational remote sensing of tropospheric aerosol over land from EOS moderate resolution imaging spectroradiometer, J. Geophys. Res.-Atmos., 102, 17051-17067, 1997 b.

Kaufman, Y. J., Gobron, N., Pinty, B., Widlowski, J., and Verstraete, M. M.: Relationship between surface reflectance in the visible and mid-IR used in MODIS aerosol algorithm - theory, J. Geophys. Res., 29), 2116, doi:10.1029/2001GL014492, 2002.

Liu, Y., Paciorek, C., and Koutrakis, P.: Estimating The Spatial and Temporal Variability of $\mathrm{PM}_{2.5}$ Concentrations in Massachusetts Using Satellite Data, Meteorological, and Land Use Information, Environ. Health Persp., 117, 886-892, 2009.

Levy, R. C. and Pinker R. T.: Remote sensing of spectral aerosol properties: a classroom experience, B. Am. Meteorol. Soc., 88, 25-30, 2007.

Levy, R. C., Remer, L. A., and Dubovik, O.: Global aerosol optical properties and application to Moderate Resolution Imaging Spectroradiometer aerosol retrieval over land, J. Geophys. Res.Atmos., 112, D13210, doi:10.1029/2006JD007815, 2007a.

Levy, R. C., Remer, L. A., Mattoo, S., Vermote, E. F., and Kaufman, Y. J.: Second-generation operational algorithm: Retrieval of aerosol properties over land from inversion of Moderate Resolution Imaging Spectroradiometer spectral reflectance, J. Geophys. Res.-Atmos., 112, D13211, doi:10.1029/2006JD007811, 2007b.

Levy, R. C., Remer, L. A., Tanré, D., Mattoo, S. and Kaufman, Y.J.: Algorithm for remote sensing of tropospheric aerosol over dark targets from MODIS: Collections 005 and 051. Revision 2, available at: http://modis-atmos.gsfc.nasa.gov/_docs/ATBD_ MOD04_C005_rev2.pdf (last access: 15 November 2015), 2009.

Levy, R. C., Remer, L. A., Kleidman, R. G., Mattoo, S., Ichoku, C., Kahn, R., and Eck, T. F.: Global evaluation of the Collection 5 MODIS dark-target aerosol products over land, Atmos. Chem. Phys., 10, 10399-10420, doi:10.5194/acp-10-10399-2010, 2010.

Levy, R. C., Mattoo, S., Munchak, L. A., Remer, L. A., Sayer, A. M., Patadia, F., and Hsu, N. C.: The Collection 6 MODIS aerosol products over land and ocean, Atmos. Meas. Tech., 6, 29893034, doi:10.5194/amt-6-2989-2013, 2013.

Li, C., Lau, A., Mao, J., and Chu, D.: Retrieval, validation, and application of the 1-km aerosol optical depth from MODIS measurements over Hong Kong, IEEE T. Geosci. Remote, 43, 26502658, 2005.

Li, S. S., Chen, L. F., Tao, J. H., Hand, D., Wang, Z. T., Su, L., Fan, M., and Yu, C.: Retrieval of aerosol optical depth over bright targets in the urban areas of North China during winter, Science China, 55, 1545-1553, doi:10.1007/s11430-012-4432-1, 2012.

Munchak, L. A., Levy, R. C., Mattoo, S., Remer, L. A., Holben, B. N., Schafer, J. S., Hostetler, C. A., and Ferrare, R. A.: MODIS $3 \mathrm{~km}$ aerosol product: applications over land in an urban/suburban region, Atmos. Meas. Tech., 6, 1747-1759, doi:10.5194/amt-6-1747-2013, 2013.

Remer, L. A., Kaufman, Y. J., Tanre, D., Mattoo, S., Chu, D. A., Martins, J. V., Li, R. R., Ichoku, C., Levy, R. C., Kleidman, R. G., Eck, T. F., Vermote, E., and Holben, B. N.: The MODIS Aerosol Algorithm, products, and validation, J. Atmos. Sci.-Special Edition, 62, 947-973, 2005.

Remer, L. A., Mattoo, S., Levy, R. C., and Munchak, L. A.: MODIS $3 \mathrm{~km}$ aerosol product: algorithm and global perspective, Atmos. Meas. Tech., 6, 1829-1844, doi:10.5194/amt-6-1829-2013, 2013.

Tanré, D., Kaufman, Y. J., Herman, M., and Mattoo, S.: Remote sensing of aerosol properties over oceans using the MODIS/EOS spectral radiances, J. Geophys. Res., 102, 1697116988, doi:10.1029/96JD03437, 1997.

United Nations: World Urbanization Prospects: The 2014 Revision, Highlights, Department of Economic and Social Affairs, Population Division, ST/ESA/SER.A/352, 2014.

van Donkelaar, A., Martin, R. V., Brauer, M., Kahn, R., Levy, R., Verduzco, C., and Villeneuve, P. J.: Global estimates of ambient fine particulate matter concentrations from satellitebased aerosol optical depth: development and application, Environ. Health Perspect., 118, 847-855, doi:10.1289/ehp.0901623, 2010.

van Donkelaar, A., Martin, R. V., Brauer, M., and Boys, B. L.: Use of Satellite Observations for Long-Term Exposure Assessment of Global Concentrations of Fine Particulate Matter, Environ. Health Perspect., 123, 135-143, doi:10.1289/ehp.1408646, 2015.

Vermote, E. F. and Kotchenova, S.: Atmospheric correction for the monitoring of land surfaces, J. Geophys. Res., 113, D23S90, doi:10.1029/2007JD009662, 2008.

Vermote, E. F., El Saleous, N., Justice, C. O., Kaufman, Y. J., Privette, J. L., Remer, L., Roger, J. C., and Tanré, D.: Atmospheric correction of visible to middle-infrared EOS-MODIS data over land surfaces: Background, operational algorithm and validation. J. Geophys. Res.-Atmos., 102, 17131-17144, doi:10.1029/97JD00201, 1997.

Wang, J. and Christopher, S. A.: Intercomparison between satellitederived aerosol optical thickness and $\mathrm{PM}_{2.5}$ mass: implications for air quality studies, Geophys. Res. Lett., 30, 2095, doi:10.1029/2003GL018174, 2003.

Wong, M., Nichol, J., and Lee, K.: An operational MODIS aerosol retrieval algorithm at high spatial resolution, and its application over a complex urban region, Atmos. Res., 99, 579-589, doi:10.1016/j.atmosres.2010.12.015, 2011.

Zha, Y., Wang, Q., Yuan, J., Gao, J., Jiang, J., Lu, H., and Huang, J.: Improved retrieval of aerosol optical thickness from MODIS measurements through derived surface reflectance over Nanjing, China, Tellus B, 63, 952-958, doi:10.1111/j.16000889.2011.00545.x, 2011. 